\title{
A INTELIGÊNCIA DO ORIENTADOR
}

\author{
Antonio José Romera Valverde \\ Professor do Departamento de Fundamentos Sociais e Jurídicos da Administração \\ da FGV-EAESP e do Departamento de Filosofia da PUC-SP. \\ E-mail:valverde@fgvsp.br
}

\begin{abstract}
"Il reste d'un homme ce que donnent à songer son nom, et les oeuvres qui font de ce nom un signe d'admiration, de haine ou d'indefférence. Nous pensons qu'il a pensé, et nous pouvons retrouver entre ses oeuvres cette pensée qui lui vient de nous: nous pouvons refaire cette pensée à l'image de la nôtre."

(Paul Valéry - Introduction à la méthode de Léonard de Vinci)
\end{abstract}

Maurício Tragtenberg foi meu orientador para dissertação de mestrado, que, uma vez pronta, se transformou, com adaptações necessárias, em tese doutoral defendida na Unicamp.

Maurício ingressou nessa universidade, como professor convidado, durante o segundo semestre de 1976. Anteriormente, perdera cargos da rede pública, vítima da "redentora", e fora boicotado em vários concursos da Unesp, mesmo tendo sido aprovado em primeiro lugar em todos eles. Uma vez na Unicamp, ofereceu um curso sob o título aparentemente rotineiro de "Metodologia Histórica". Ensinou a ler Marx, $O$ capital, e Weber, $A$ ética protestante, com rigor e pontualidade, porém sem o ranço do método estruturalista ainda em moda na academia. O substrato do curso era a junção entre esses autores, que já havia estudado em sua obra mais conhecida, Burocracia e ideologia. Contudo, por aquela porta de entrada para o mundo da Filosofia Política e da História, forneceu munição teórica para muito mais do que o curso exigia. Sugeriu Paul Mattick, Karl Korsch, Alexandra Kollontaï, Lucien Sebag, Anton Panneköek, Marcuse, Linhart, Guy Debord, Tocqueville e até mesmo Ibn Khäldun, o Maquiavel árabe. Para o meu caso, egresso da Filosofia, intoxicado por Fenomenologia, indicou-me dois antídotos homeopáticos: Fenomenologia y materialismo dialéctico, do vietnamita Tran-Duc-Thao, e Introduction à la phénoménologie, de J. T. Desanti. Funcionaram como tábua de salvação.

A marca essencial de Maurício Tragtenberg - que me deixou siderado - era sua inteligência, tudo mais acidentes e derivações. Inteligência como Otto Maria Carpeaux reconheceu em Maquiavel ao afirmar: "A inteligência é coisa mais rara do que se pensa. E Maquiavel foi um dos homens mais inteligentes de todos os tempos" (Carpeaux, 1999, p. 778). A de Maurício sempre evoca algumas passagens tópicas da Filosofia que se encontram, de certa forma, na contramão do próprio desenvolvimento da História da Filosofia.

Matizo, inicialmente, com uma passagem de A Gaia ciência. Nietzsche (1978, p. 200) escreveu: "O intelecto, através de descomunais lances de tempo, não engendrou nada além de erros; alguns deles resultaram úteis e conservadores da espécie: quem topou com ele ou os recebeu como legado combatia seu combate por si mesmo e por sua prole com maior felicidade. Tais errôneos artigos de crença, que eram sempre legados mais adiante e afinal se tornaram quase o espólio e o fundo comum da humanidade, são, por exemplo, estes: que há coisas que duram, que há coisas iguais, que há coisas, matéria, corpos, que uma coisa é como sempre aparece, que nosso querer é livre, que o que é bom para mim também é bom em e para si. Só muito tarde vieram os que negavam e punham em dúvida tais proposições - só muito tarde veio a verdade, como a forma menos forte do conhecimento. Parecia que com ela não se conseguia viver, nosso organismo era feito para o contrário dela; todas as funções superiores, as percepções dos sentidos e toda espécie de sensação em geral cooperavam com aqueles antiquíissimos erros fundamentais incorporados. Mais ainda: aquelas proposições se tornavam, mesmo no interior do conhecimento, as normas segundo as quais se mediam 'verdade' e 'inverdade'..."

Outra recorrência - ainda na contramão - é a oitava tese de Ad Feuerbach, em que se lê: "Toda vida social é 
essencialmente prática. Todos os mistérios, que induzem às doutrinas do misticismo, encontram sua solução racional na praxis humana e no compreender dessa praxis" (Marx, 1978, p. 52).

Essas passagens ilustram meu preito de gratidão a Maurício, pois, como orientador, me fez "cair na real". Puxava-me para a terra, como a dizer que quanto mais próximo dela, da realidade, tanto mais humano, verdadeiro, científico. Ficam de fora os falsos brilhos da linguagem empoada dos filósofos da moda. Isso não quer dizer que fosse empirista nem cético. Foi um pensador inserido na melhor tradição do pensamento negativo, de matriz hegeliana. O pensar, a abstração, a elevação conceitual, tinham um nexo dialético com a história presente e seus "horizontes de negação". Não às alturas metafísicas - às altitudes escorregadias do Ser -, mas, contraditoriamente, ao grande mundo, ao universal soerguido das profundezas efêmeras do cotidiano, da tragédia humana diária. Entre o ontológico e o ôntico, reconhecia o valor do primeiro, mas privilegiava o segundo a participação do homem na História. Esse aprendizado devo a ele.

Devo a ele também o fato de redigir notas de rodapé weberianas, que não somente fundamentassem o texto escrito, mas que lhe dessem porosidade. Há uma anedota corrente no meio acadêmico de que um orientando apresentou uma tese com notas de rodapé tão expressivas, que outros pós-graduandos puderam utilizá-las como fonte de temas e problemas para outros tantos trabalhos. Psicologia do rumor à parte, a precisão da pesquisa e sua indicação foram uma constante no trabalho sob orientação de Tragtenberg.

Pela Literatura, Maurício iniciara o conhecimento do grande mundo. Lera bastante Dostoiévski desde a adolescência. Empapou-se de literatura russa, mas não só de Dostoiévski e Gorki nem só de literatura russa. O dilema da liberdade absoluta da personagem Raskolnikov, a volúpia do ato impulsivo de delegar a liberdade - como suposta necessidade humana - na palavra do nonagenário cardeal inquisidor dos Irmãos Karamazov e os heróis absurdos como Kirilov, de Os possessos, eram recorrências constantes em suas preleções.

Por ser autodidata, os aspectos libertários de sua vida e obra são plenos de características bastante particulares, tanto do ponto de vista teórico quanto histórico. Tragtenberg descende de imigrantes judeus ucranianos, que chegaram ao Brasil fugidos "das perseguições da Rússia czarista e dos progoms da década de 10" (Tragtenberg, 1999, p. 11). Sua família residiu, de início, no Rio Grande do Sul, mais precisamente "na zona da colonização de camponeses de origem judaica"
(Tragtenberg, 1999, p. 11) em Erebango, depois chamada de Erexim, atualmente Getulio Vargas. Em seguida, mudou-se para Porto Alegre e mais tarde para a cidade de São Paulo.

Órfão de pai, desde a primeira infância, como tantos outros pensadores - Rousseau, Sartre, Darcy Ribeiro... livre das injunções paternas, diluiu outra parte do superego aos 15 anos quando, diante do dilema "judeu ou cristão", se tomou por ateu. "Por seu ser ateu..." (Tragtenberg, 1991, p. 85). Dizia de si mesmo: "Ateu, graças a Deus!” Mas

\section{Pela Literatura, Maurício} INICIARA O CONHECIMENTO DO

\section{GRANDE MUNDO. LERA BASTANTE DOSTOIÉVSKI DESDE A} ADOLESCÊNCIA. EMPAPOU-SE DE LITERATURA RUSSA, MAS NÃO SÓ DE LITERATURA RUSSA.

nunca deixou de ser judeu, assim como Einstein: "A natureza da concepção judaica da vida se traduz assim: direito à vida para todas as criaturas. A significação da vida do indivíduo consiste em tornar a existência de todos mais bela e mais digna. A vida é sagrada, representa o supremo valor a que se ligam todos os outros valores. A sacralização da vida supra-individual incita a respeitar tudo quanto é espiritual - aspecto particularmente significativo da tradição judaica.

O judaísmo não é uma fé. O Deus judeu significa a recusa da superstição e a substituição imaginária para este desaparecimento... Compreende-se claramente que 'servir a Deus' equivale a 'servir à vida'. Com esta finalidade, as melhores testemunhas do povo judeu, em particular os profetas e Jesus, se bateram incansavelmente... O judaísmo não é uma religião transcendente. Ocupa-se unicamente da vida que se leva, carnal por assim dizer, e de nada mais. Julgo problemático que possa ser considerado como religião no sentido habitual do termo, tanto mais que não se exige do judeu nenhuma crença, mas antes o respeito pela vida no sentido suprapessoal... Com efeito, Deus não existe para o judaísmo, onde o respeito excessivo pela letra esconde a doutrina pura. Contudo considero o judaísmo como um dos simbolismos mais puros e mais vivos da idéia de Deus, sobretudo porque 
recomenda o princípio do respeito à vida" (Einstein, 1981, p. 114-115).

Nunca abandonou o viés "sapiencial" do judaísmo, mesmo sem a prática, sem a exterioridade da religião. Reconheceria, como o pai da teoria da relatividade, que "a paixão pelo conhecimento em si mesmo, a paixão da justiça até o fanatismo e a paixão da independência pessoal exprimem as tradições do povo judeu e considero minha pertença a esta comunidade como um dom do destino" (Einstein, 1981, p. 113).

\section{MaURícIo PUXAVA-ME PARA}

\section{A TERRA, COMO A DIZER QUE \\ QUANTO MAIS PRÓXIMO DELA,}

\section{DA REALIDADE, TANTO MAIS}

\section{HUMANO, VERDADEIRO, CIENTÍFICO.}

Morador do bairro paulistano do Bom Retiro, tradicional ex-reduto judaico, aliviara ainda outra parte do superego: a tendência familiar, digamos, mais mercantil, pelas leituras de romances de cunho social, jornais operários e revistas de divulgação científica. Com um pequeno detalhe: em iídiche - o "jargão do alemão medieval, que o judeu da Alemanha desenvolveu em função da integração na sociedade alemã” (Tragtenberg, 1999, p. 16).

Aprendeu sozinho francês, inglês, alemão. Para a aprendizagem do italiano, os Abramo colaboraram. O catalão veio da freqüentação do Centro de Cultura Social, no bairro do Brás, onde refugiados da Guerra Civil Espanhola compareciam, local também de ensino mútuo - prática comum nos meios anarquistas. Desenvolveu um método próprio de aprendizagem de línguas. Reunia por ordem alfabética as palavras conhecidas e pesquisava em dicionários da Biblioteca Mário de Andrade o significado das desconhecidas. Registrou: "Já possuía a essa altura uma espécie de 'capital lingüístico' que dava para o gasto; do conhecimento da língua iídiche por via familiar cheguei ao alemão e às traduções de Weber... o francês aprendi com minha companheira, que fora professora de francês do $2^{\circ}$ grau. A língua inglesa, através da consulta direta ao dicionário na formação de um vocabulário inglês especializado na área de ciências sociais" (Tragtenberg, 1991, p. 86).

Tarefa árdua, mas logo traduziu Freud, O parricídio, para o jornal Vanguarda Socialista, órgão de publicidade do Partido Socialista, liderado em São Paulo por Antônio
Cândido e Phebus Gikovate. Aliás, o primeiro, Florestan Fernandes e Hermínio Saccheta "orientaram" seu autodidatismo. Caso contrário, dizia, todo seu esforço redundaria num "saber selvagem" ou, como queriam os gregos, em "polimatia", o saber de coisas desconexas. Como lembrou reiteradas vezes, a família Abramo, o Centro de Cultura Social, a Biblioteca Mário de Andrade, o Partido Socialista, foram "minhas universidades" - parafraseando título de romance homônimo de Máximo Gorki. Praticou autodidatismo, com recorrência ao "ensino mútuo", como faziam os libertários. E, como queria Proudhon, "todo autodidata é um livre pensador". Maurício pareceu personificar à medida essa sentença.

Era de uma autenticidade incrível, que fazia dele pessoa ímpar, diferente de todos os professores que tenho conhecido na academia. Mesmo tendo se tornado intelectual sobejamente reconhecido, galgado a carreira acadêmica em instituições de ponta - titular da Fundação Getulio Vargas, da PUC-SP e da Unicamp -, publicado obras fundamentais e oportuníssimas, nunca adentrou o universo ideológico/consumista da classe média. O que provocava admiração e, no mesmo passo, um certo desconforto entre os colegas.

Se, como quer o poeta, "a viagem é um vácuo no tempo", Maurício deixou o espírito da viagem passar. Tal qual Racine, Kant, Machado de Assis, que não necessitaram viajar - pois o grande mundo passava por eles -, Tragtenberg se ausentou do país uma só vez, indo à Argentina adquirir livros para escrever sua tese. Afinal, os clássicos são estáveis!

Do universo da praxis interessou-se pela autogestão das organizações populares, pela autonomia operária, pela educação libertária e apoio às traduções de textos, sobretudo de talhe libertário. Seus temas recorrentes mais comuns foram: Nestor Makno e Kronstadt; Buenaventura Durruti e a Guerra Civil Espanhola; comissões de fábrica - de inspiração gramsciana - da Ford de São Bernardo e os debates nas Comunidades Eclesiais de Base, sobretudo da região paulistana do Butantã; Francisco Ferrer e a pedagogia libertária. Neste último aspecto, a Faculdade de Educação da Unicamp funcionou como seu laboratório, pois, fisicamente, a dois passos dela, encontra-se o Arquivo Edgar Leuenroth, que contém praticamente todas as publicações anarquistas e de cunho sindical publicadas desde o início do século XX. Quando adolescente, lera todo esse material em freqüência diária aos anarquistas do Brás.

Os muros da universidade sempre foram muito restritivos para ele. Sua praxis fez também com que mantivesse por dez anos a coluna "No Batente", do jornal Notícias Populares. Semanalmente, respondia cartas, publicava 
artigos, polemizava. Seus temas prediletos foram: sindicalismo, racismo, feminismo, educação, política nacional e internacional, etc. Em linguagem extremamente acessível, praticava um jornalismo opinativo, tão ausente nos dias que correm. Sucesso de público.

Quanta falta ele nos faz! Quem melhor que Maurício Tragtenberg poderia criticar com altura intelectual e perspectiva política de esquerda, sem fisiologismos, os PCNs - os Parâmetros Curriculares Nacionais -, para não irmos muito longe e fugirmos de nosso métier?

Lembro-me de uma vez que o encontrei aqui na GV para uma sessão de orientação. Andava um tanto atrapalhado e deixei escapar uma ou duas querelas. Olhou-me, serenamente, e perguntou: "você é adepto da filosofia do coitadismo?" Levei um tremendo susto e começamos a rir. No processo da desorientação, como ele mesmo dizia, em vários momentos reproduziu-se essa espécie de "cura", mas, claro, para querelas intelectuais. Nunca perdeu a irreverência e o humor - emblemas do seu socialismo libertário, mesmo que nunca tenha se declarado anarquista, assim como Tolstói. O humor talvez seja doce herança de leituras de Maquiavel, Nietzsche e dos sofistas, que citava a mancheias. Maurício fazia rir com suas tiradas: "aqui só a biologia resolve!", "isto é cultura da desconversa" (paráfrase de Mário de Andrade), "reformar para não mudar nada", "você está com encosto?", "a história é um pesadelo" (paráfrase de James Joyce), "não voto em nome, voto em história pessoal". Parecia mesmo não ser atingido pelo superego, como ironizava Joel Martins, seu antigo professor no tempo em que cursou a licenciatura de História, na Universidade de São Paulo.
Com os orientandos e em seus textos, Maurício praticava a crítica da razão iluminista, mas sem perder de vista sua importância cultural e suas possibilidades no universo dos "esclarecimentos", mesmo circulando muitas vezes por paragens próximas da contracultura.

Herdeiro do professor Cruz Costa, que apregoava o entendimento do pensamento brasileiro como objeto e fim do trabalho de intelectuais nativos, Tragtenberg entremeava, no mesmo passo, cursos teóricos com outros que tratavam do pensamento político brasileiro. Analisou, em vários momentos, o tema da "conciliação" na política nacional, desde o gabinete Paraná (1842), sombreado pela filosofia do ecletismo cousiniano. Criticou e contextualizou ideólogos como Torres Homem, Justiniano José da Costa, Tavares Bastos, Joaquim Nabuco, Oliveira Lima, Oliveira Vianna, Nestor Duarte. Deste último, autor de A ordem privada e organização política nacional, Tragtenberg garantia que a obra corroborou na formação ideológica da UDN (Duarte, 1939). As recorrências para tal crítica moviam-se - por vezes de par com o enquadramento teórico, de viés weberiano, operado por Raymundo Faoro, que admirava.

Termino, sem concluir, recorrendo à Literatura. Por conviver com Maurício e ter aprendido a desconfiar das "verdades" que vieram mais tarde, depois de "descomunais lances de tempo", como "invenções" de sábios, a milhas de distância da realidade, a tirada de Guimarães Rosa bem cumpre a função de fecho desta homenagem: "comprei uns óculos,/ óculos dos mais excelentes,/ não têm aros, não têm asas,/ não têm grau e não têm lentes..." ○

\section{REFERÊNCIAS BIBLIOGRÁFICAS \\ CARPEAUX, Otto Maria. Inteligência de Maquiavel. Rio de Janeiro : Topbooks/UniverCidade, 1999. v. I. Ensaios Reunidos, 1942-1978. \\ DUARTE, Nestor. A ordem privada e a organização política nacional: contribuição à sociologia política brasileira. São Paulo : Nacional, 1939. (Coleção Brasiliana, v. 172).}

EINSTEIN, Albert. Como vejo o mundo. Tradução de H.
NOTA

Texto apresentado no Evento "Homenagem a Maurício Tragtenberg", realizado em 6 de novembro de 2000,
P. de Andrade. 2. ed. Rio de Janeiro : Nova Fronteira, 1981.

MARX, Karl. Manuscritos econômico-filosóficos e outros textos escolhidos. Tradução de José Carlos Bruni et al. 2. ed. São Paulo : Abril Cultural, 1978. (Coleção Os Pensadores).

NIETZSCHE, Friedrich. Obras incompletas. Tradução de Rubens Rodrigues Torres Filho. 2. ed. São
Paulo : Abril Cultural, 1978. (Coleção Os Pensadores).

TRAGTENBERG, Maurício. Memorial - Maurício Tragtenberg. Pro-Posições, Campinas, n. 4, 1991. Revista da Faculdade de Educação da Unicamp.

TRAGTENBERG, Maurício. Memórias de um autodidata no Brasil. São Paulo : Escuta, 1999 promovido pelo Departamento de Fundamentos Sociais e Jurídicos da Administração da FGV-EAESP. 


\title{
MAURÍCIO TRAGTENBERG: DESVENDANDO IDEOLOGIAS
}

\author{
Fernando C. Prestes Motta \\ Professor do Departamento de Administração Geral \\ e Recursos Humanos da FGV-EAESP. \\ E-mail: fmotta@fgvsp.br
}

Maurício Tragtenberg não foi apenas um grande sociólogo, foi também um dos fundadores mundiais da teoria crítica das organizações, hoje um campo prolífero em vários países. A produção acadêmica de Maurício guarda uma grande especificidade: em primeiro lugar, quebra o tabu de trabalhar Marx e Weber em um mesmo texto; em segundo lugar, rompe com o marxismo ortodoxo, em direção a um marxismo "autogestinário", em que a influência de várias tendências se faz sentir, inclusive as anarquistas.

\section{Marcou a todos \\ - Maurício bondoso,}

QUE DISTRIBUÍA REFERÊNCIAS

BIBLIOGRÁFICAS ENTRE OS

COLEGAS E ALUNOS, ATÉ

QUANDO ESTES NÃO AS PEDIAM.

Marx é para Maurício o teórico por excelência da estrutura, da base econômica, enquanto Weber é por excelência o teórico da superestrutura política e ideológica da sociedade. Antes de Tragtenberg, e dos primeiros que lhe seguiram os passos, isso era uma blasfêmia. Uma tese, por exemplo, tinha que ser totalmente e exclusivamente weberiana. Esse duplo uso fica claro, por exemplo, no mais importante de seus livros, Burocracia e ide- ologia, publicação de sua tese de doutoramento na USP, que rompe com inúmeros preconceitos e lança as sementes de muitas teorizações posteriores (Tragtenberg, 1974).

O livro trata das teorias administrativas como ideologias da burocracia e funda esta última no modo de produção asiático. Pouquíssimas pessoas tinham teorizado sobre esse modo de produção, e o estudo de Maurício abriu caminho para que muitos trabalhassem nessa linha de reflexão. Os capítulos mais importantes do livro são todos os seus capítulos. Maurício trabalha na linha de erudição que lhe era própria, tanto no "Modo de Produção Asiático" quanto em "As Harmonias Administrativas de Saint-Simon a Elton Mayo", assim como no capítulo sobre Weber, sobre a "Crise da Consciência Liberal Alemã" e em "Burocracia: da Mediação à Dominação". Foi um grande golpe na mainstream da teoria organizacional e a semente da teoria crítica no Brasil.

Outros livros de Maurício Tragtenberg sobre participacionismo e sobre educação também são relevantes para a teoria organizacional. É interessante lembrar $A$ delinqüência acadêmica: o poder sem saber e o saber sem poder e o ensaio "A escola como organização complexa”. Em alguns desses trabalhos, aparece o Maurício mais acadêmico, em outros, o Maurício mais militante. Sempre, porém, o Maurício estudioso e erudito (Tragtenberg, 1976, 1979).

O que nem sempre fica claro é o Maurício bondoso, que distribuía referências bibliográficas entre os colegas e alunos, até quando estes não as pediam. Por vezes, as referências vinham acompanhadas do nome da livraria e da localização em suas estantes. 
No início dos anos 70, tive um esgotamento que tornava difícil a tarefa de dar aulas. Maurício soube, organizou um grupo de professores do qual faziam parte Liliana Segnini e Lúcia Bruno, e o curso foi dado.

Também nem sempre fica claro o Maurício provocador. Certa vez, eu era professor da Escola de Administração de Empresas de São Paulo da Fundação Getulio Vargas e fazia também o doutorado. Tinha, como Maurício, um contato muito grande com os alunos de graduação. Alguns deles me disseram que faziam um curso muito interessante com Tragtenberg. Resolvi assistir a uma aula. Acho que escolhi um mau dia, pois o professor passou uma "bronca" nos alunos, por causa do número de faltas, e o clima não era dos mais amigáveis. De qualquer forma, logo que a aula começou, resolvi discordar dele citando Gramsci. Maurício me olhou e disse: "Você não leu Proudhon nem Bakounine, como é que quer discordar?" Proudhon foi o objeto da minha tese de doutorado e Maurício estava na banca. A nota foi dez.

É muito difícil indicar as influências de Maurício em minha obra. Às vezes, a influência parece muito forte, outras vezes, quase nenhuma. Freqüentemente, começávamos a nos interessar por um determinado tema, sem que tivéssemos nenhum contato prévio. No entanto, existe uma marca indiscutível de sua influência na maioria dos meus trabalhos - que varia de intensidade, mas que está sempre presente. Felizmente posso dizer que a marca mais intensa está no livro que mais aprecio, intitulado Organização e poder: empresa, Estado e escola.

$\mathrm{Na}$ trilha aberta por Claude Lefort - que, em Elementos de uma crítica da burocracia, sustenta que esta última é um grupo social que faz prevalecer um certo tipo de organização, consoante o estado da técnica e da economia, que só é o que é em função de uma atividade social e que implica um sistema de condutas significativas -, procuro explorar a hipótese de que a tecnoburocracia é uma classe social constitutiva do capitalismo, que vive para a manutenção e ampliação de seu próprio poder, que faz prevalecer um tipo de organização em constante mutação, com marcos claros nas diversas formas de cooperação que caracterizam o capitalismo: manufatura e indústria (Marx) e automação (Naville); que tem seu campo de existência determinado pelas condições gerais de produção e pela gestão dos processos particulares de fabrico (João Bernardo); que apresenta uma certa homologia com a organização pré-capitalista derivada da cooperação simples (Marx, Tragtenberg), isto é, com a burocracia patrimonial (Weber, Balazs); que tem na teoria das organizações convencional (mainstream), produzida nos países desen- volvidos, a expressão ideológica mais clara de sua prática e que se reproduz enquanto classe, primordialmente, via capital cultural objetivado e capital social (Bourdieu), de onde decorre o valor de posição da escola, tanto pela estratégia de reprodução quanto pela naturalidade de sua dominação (Lefort, 1970).

\section{Maurício dizIA Que só}

\section{OS MEDÍOCRES PROCURAM}

DiscíPulos. De FATO, ELE

\section{NÃO OS TEVE, MAS TEVE}

AMIGOS QUE MARCOU

\section{PROFUNDAMENTE.}

Entendo que o método da análise é fundamentalmente marxista, fazendo de Marx uma leitura autonomista e, para tanto, recorrendo a pensadores como João Bernardo, Mário Tronti, Antonio Negri, Claude Berger e outros menos comprometidos com Marx, como Castoriadis e Guattari. Entretanto, como, a meu ver, o marxismo ainda não desenvolveu instrumentos adequados à análise superestrutural, recorro, para esse fim, e só nesse aspecto, a autores como Weber, Bourdieu e outros (Motta, 1986). Ainda assim, a utilização de referenciais teóricos tão diversos é pelo menos tão heterodoxa quanto o tema tratado.

Maurício dizia que só os medíocres procuram discípulos. De fato, ele não os teve, mas teve amigos que marcou profundamente. Notam-se essas marcas no percurso de vários intelectuais que tiveram ou não contato direto com ele. Entre elas, uma especialmente forte está naquilo que considero a verdadeira tese de seu livro Burocracia e ideologia, expressa da seguinte maneira: "A Teoria Geral da Administração é ideológica, na medida em que traz em si a ambigüidade básica do processo ideológico, que consiste no seguinte: vincula-se às determinações sociais reais, enquanto técnica (de trabalho industrial, administrativo, comercial) por mediação do trabalho e afasta-se dessas determinações sociais reais, compondo-se num universo sistemático organizado, refletindo deformadamente o real, enquanto ideologia" (Tragtenberg, 1974, p. 89).

Recentemente, no XXIV Enanpad, em 2000, Ana Paula Paes de Paula apresentou um ensaio baseado nessa tese, procurando mostrar, entre outras coisas, a atua- 
lidade daquilo que Maurício fez com relação à Escola Clássica e à Escola de Relações Humanas, teorias do início do século, análise dos anos 70.

Paes de Paula revisita o pensamento de Tragtenberg, formulando quatro teses que utiliza como referências para analisar o que chama "novas" teorias administrativas e realidades organizacionais. É a partir de tais teses que procura demonstrar que tanto o "fordismo" quanto o "toyotismo" refletem interesses socioeconômicos dominantes, além de possuírem caráter ideológico - já que suas idéias e práticas endossam tais interesses -, ao mesmo tempo em que amenizam as tensões entre capital e trabalho, perpetuando o que Maurício chama de ideologia da "harmonia administrativa", que ele vê nascer em Saint-Simon, no século XIX.

\section{O pensamento de Maurício}

\section{TRAGTENBERG REVELA-SE}

\section{EXTREMAMENTE FORTE PARA}

\section{A ANÁLISE DA EVOLUÇÃO DA}

\section{SOCIEDADE E DA ECONOMIA}

\section{MUNDIAL APÓS A HEGEMONIA \\ DO "TAYLORISMO" E DA ESCOLA \\ DE RELAÇÕES HUMANAS.}

Da mesma forma, a burocracia também adaptou-se às condições da época, tornando-se mais flexível para atender às demandas mais recentes da tecnologia e do mercado, criando novos instrumentos de controle e tornando-se mais sofisticada enquanto aparelho ideológico reprodutor da dominação, dando origem, desse modo, a uma nova noção de burocracia - a burocracia "flexível” -, e não a uma organização pós-burocrática ou pósmoderna.

O pensamento de Maurício Tragtenberg revela-se extremamente forte para a análise da evolução da sociedade e da economia mundial após a hegemonia do "taylorismo" e da escola de relações humanas, bem como dos modelos administrativos gerados nesses anos. "Fordismo" e "Toyotismo" refletem os interesses dominantes além de exibirem um claro caráter ideológico. Elaboram, como indiquei, idéias e práticas que legitimam esses interesses e tornam mais amenas as tensões entre capital e trabalho que caracterizam toda a história do capitalismo. Do mesmo modo, seguindo a linha de Saint-Simon, Taylor e Fayol e Elton Mayo, perpetuam a ideologia da "harmonia administrativa".

Paes de Paula sublinha o fato de as idéias "toyotistas" serem um desenvolvimento de teorias administrativas antigas, sendo inadequado para elas o adjetivo "pósfordistas". Tais idéias e teorias obedecem a um princípio genético. Da mesma forma que as idéias, modelos e teorias, a burocracia adaptou-se aos novos tempos, como já afirmei, tornando-se mais flexível para fazer face às mudanças na tecnologia e no mercado, aperfeiçoando e criando instrumentos de controle e tornando-se um aparelho ideológico de dominação na sociedade extremamente sofisticado e originando a "burocracia flexível", noção que nos ajuda a pensar nas transformações por que passa tal fenômeno desde Max Weber, mesmo que a leitura atenta desse sociólogo mostre que o fenômeno em sua essência seja o mesmo.

A propagação da falácia da "desburocratização", que tanto encantou burocratas de todos os níveis e escalões, seja na área pública, seja na área privada, ao concentrar-se no formalismo e impessoalidade, características do tipo ideal de Max Weber, desviou a atenção para o que há de mais precioso no seu pensamento em termos de sociologia da dominação, isto é, a burocracia como dominação. Trata-se de uma nova operação ideológica que busca a maximização da "harmonia administrativa".

A atualidade do pensamento de Tragtenberg é a atualidade de todas as suas qualidades intelectuais e humanas. Essencial a sua luta contra a dominação e a exploração. É por esta razão que sua obra é tão necessária para refletir sobre as possibilidades de emancipação humana e sobre as possibilidades de construção de uma sociedade igualitária e justa. Da mesma maneira, sua obra é essencial para se pensar a verdadeira democratização das relações de trabalho.

A História está sempre nos colocando novas realidades, a Ciência e a tecnologia nos atropelam com seus avanços, a construção de uma sociedade democrática é sempre algo almejado, mas difícil. A questão da liberdade, há séculos desafiando e encantando os estudiosos, começa a ganhar um novo interesse, diante de todos os novos fenômenos. A emancipação virá após alcançarmos novos e mais altos patamares científicos e tecnológicos? A resposta a essa questão é muito mais complexa do que muitas formas de compreensão de nossa realidade parecem sugerir. Para Paes de Paula, ela depende de transcender a noção de democracia como consenso, pensando-a como conflito, como uma participação verda- 
deira no processo de tomada de decisões, bem como na partilha de poder.

Deve-se considerar também que a dificuldade de se conquistar a emancipação no interior das organizações tem provocado sua busca no âmbito extra-organizacional. Visões alternativas da emancipação humana vão ganhando espaço como a sociedade do "ócio criativo" e a ideologia do "empreendedorismo", mas elas precisam ser pensadas com cautela. A primeira entende que teremos todo o tempo livre para o ócio e a criatividade, graças ao desenvolvimento da Ciência e da tecnologia. Fundamenta-se na noção de Marx, segundo a qual o desenvolvimento das forças produtivas poderia tornar o trabalho uma atividade lúdica. Maurício também usou Marx para tratar da mesma questão, sendo porém mais fiel à perspectiva marxista. A tecnologia, segundo ele, não seria suficiente para libertar o trabalhador. A emancipação refere-se diretamente ao modo como as forças sociais se relacionam, que pode resultar tanto em opressão quanto em libertação.

A segunda visão, do "empreendedorismo", vê a liberdade no autogerenciamento. É a idealização do trabalho autônomo. Técnicas e idéias anteriormente circunscritas ao treinamento empresarial são agora disponíveis a qualquer interessado, exacerbando o individualismo e criando uma falsa sensação de liberdade. Essa ideologia contribui para a desmobilização política, afastando-nos das vias de democratização.

A opressão não encontra qualquer lugar na obra de Tragtenberg. Não conheço crítica mais tenaz. Hierarquias explícitas e disfarçadas não encontram guarida. É bem possível que o maior legado de sua obra seja a esperança por trás do alerta para as armadilhas ideológicas que nos desviam da liberdade, pela "falácia da harmonia" (Paes de Paula, 2000). As formas ritualistas, pobres em conteúdo, seja na escola, na empresa ou na sociedade, o poder sem saber e o saber sem poder, eram tratados de forma irônica e mordaz por Maurício, que procurava sempre as relações sociais reais escondidas na ideologia e em seus mecanismos.

Nas palavras de Liliana Segnini (1999), "a denúncia das formas de opressão, dominação e exploração e a procura do conhecimento que funda a solidariedade teceram a vida de Maurício, como intelectual ou amigo, pai ou companheiro, professor ou militante". Ciência e compromisso eram para ele sinônimos, entendido o compromisso como ético, como busca da transformação do mundo. Era intransigente nesse sentido: nunca cooptou a ciência que não tivesse como horizonte a elevação da condição humana, a dignidade do homem.

Indignava-se diante da ideologia do poder e inovava nas formas de reflexão, bem como no tratamento teórico, para denunciar os impedimentos e para que os seres humanos tomassem em suas mãos as decisões referentes aos seus destinos. Sua própria vida foi assim construída desde a infância no Rio Grande do Sul, até São Paulo, onde passou toda a sua vida adulta.

\section{A ATUALIDADE DO PENSAMENTO DE Tragtenberg É A ATUALIDAdE DE TODAS AS SUAS QUALIDADES} INTELECTUAIS E HUMANAS.

\section{ESSENCIAL A SUA LUTA CONTRA}

\section{A DOMINAÇÃO E A EXPLORAÇÃO.}

Neto de imigrantes judeus vindos da Ucrânia, Maurício Tragtenberg tinha na memória de sua família os progroms e viveu a realidade da pequena propriedade e da cultura de subsistência, cujo excedente era vendido na cidade. Com outras famílias judias, participou, ainda criança, de uma experiência baseada no apoio mútuo e na solidariedade, cuja inspiração vinha da revolução "autogestionária maknovista" na Ucrânia. Foram valores que sempre o acompanharam e que transmitiu aos que tiveram a felicidade de com ele conviver.

Era um apaixonado pelo conhecimento, lia sistematicamente e apreciava a discussão crítica. Não cursou a escola de forma regular, mas, por indicação de Antônio Cândido, pôde apresentar uma monografia à Faculdade de Filosofia, Letras e Ciências Humanas da Universidade de São Paulo. Com isso, tornou-se historiador. Dizia que era o que era graças às "universidades" que cursara, isto é, às discussões de leituras que começaram à luz de vela no Sul, em meio aos camponeses, quando liam Bakounine, Kropotkine, Tolstoi e tantos outros.

$\mathrm{Na}$ verdade, essa prática jamais foi abandonada e se prolongou com sapateiros, vidraceiros, motorneiros e muitos outros do PCB e do PSB, além de anarquistas, professores e jornalistas - enfim, com quem lhe possibilitasse acesso a uma boa leitura ou a um bom debate. Nessa trajetória, foi de especial importância a família Abramo, como Maurício sempre destacou.

Como cientista social, que foi, de fato, como acabou sendo conhecido, Tragtenberg foi professor, pesquisador e jornalista. Ministrou aulas em várias esco- 
las e estabelecimentos de ensino superior, bem como em escolas públicas de $2^{\circ}$ grau. Boa parte de sua vida acadêmica relacionou-se com a Pontifícia Universidade Católica de São Paulo, com a Universidade Estadual de Campinas e com a Fundação Getulio Vargas, em São Paulo. A generosidade marcava sua relação com os alunos e com os colegas. Com freqüência, ao encontrar um mestrando ou um doutorando, lembrava-se de seu tema de dissertação ou tese e acrescentava referências bibliográficas.

Burocracia e ideologia, seu livro ao qual já me referi e que, a meu ver, merece um destaque especial, foi publicado em 1973. Foi um trabalho pioneiro na construção de uma abordagem crítica das instituições e organizações burocráticas. Ali estão desvendadas as formas de dominação e exploração engendradas em diferentes momentos históricos com vistas ao exercício do poder.

Como tive oportunidade de salientar, Maurício rompeu nessa tese com limites teóricos anteriormente "sagrados", construindo um diálogo entre Marx e Weber. As formas de exploração encontraram possibilidade explicativa em Karl Marx. As formas de dominação encontraram possibilidade explicativa em Max Weber, seja nas organizações capitalistas, seja nas então organizações comunistas. Estudou o poder enquanto burocracia, de forma minuciosa, desde o modo de produção asiático, sobre o qual sua obra é pioneira no Brasil, até as propos- tas participacionistas. Foi um dos mais profundos conhecedores da obra de Weber no país, sem se restringir a ser um especialista.

Como relata Liliana Segnini (1999), nunca foi um intelectual ortodoxo. Jamais se contentou com respostas previamente elaboradas para problemas sociais complexos. Era comprometido com o trabalho do pensamento. Inquieto, foi um dos primeiros a analisar o regime soviético como opressor. Para ele, o "stakanovismo" não significava nada mais que a transposição do "taylorismo" e seus controles para a União Soviética, contexto que se pretendia "proletário".

Em Administração, poder e ideologia, publicado em 1980, analisou as propostas de co-gestão, que, ironicamente, denominou "Alice no País das Maravilhas", pois, concordando com Jenkis, o citava para afirmar: "ceder um pouco de poder aos trabalhadores pode ser um dos melhores meios de aumentar sua sujeição, se isto lhes der a impressão de influir sobre as coisas" (Tragtenberg, 1980).

Finalmente, Maurício Tragtenberg foi um dos primeiros intelectuais do nosso país a romper com as ortodoxias marxistas, as quais passou a compreender como fonte de opressão. Todavia, jamais se distanciou das leituras dialéticas e libertárias de Marx. Era um intelectual heterodoxo. Seu único compromisso era com a justiça social, com a melhoria da condição humana (Segnini, 1999).
REFERÊNCIAS BIBLIOGRÁFICAS

GARCIA, Walter E. (Org.). Educação brasileira contemporânea: organização e funcionamento. São Paulo : McGraw Hill do Brasil, 1976.

MOTTA, Fernando C. Prestes. Organização e poder: empresa, Estado e escola. São Paulo : Atlas, 1986.

LEFORT, Claude. Que és la burocracia. Paris : Ruedo Ibérico, 1970.

PAES DE PAULA, Ana Paula. Tragtenberg revisitado: as inexoráveis harmonias administrativas. In: ENCONTRO NACIONAL DA ASSOCIAÇÃO NACIONAL DOS PROGRAMAS DE PÓS-GRADUAÇÃO EM ADMINISTRAÇÃO, 24., 2000, Florianópolis. Anais... Florianópolis : Anpad, 2000.

SEGNINI, Liliana Roelfsen Petrilli. Maurício Tragtenberg: intelectual intransigente e amigo generoso. Conferência proferida na ANPED, 1999. (Mimeo).
TRAGTENBERG, Maurício. Burocracia e ideologia. São Paulo : Ática, 1974.

TRAGTENBERG, Maurício. A delinqüência acadêmica: o poder sem saber e o saber sem poder. São Paulo Rumo, 1979.

TRAGTENBERG, Maurício. Administração, poder e ideologia. São Paulo : Moraes, 1980. 